\title{
Being and Becoming Poor: How Cultural Schemas Shape Beliefs about Poverty
}

This is a pre-print version of a manuscript published in Social Forces March 2017, volume 95, issue 3, pages 1023-1048, published by Oxford University Press on behalf of the University of North Carolina at Chapel Hill. doi: 10.1093/sf/sox007

\author{
Patricia Homan, Lauren Valentino, and Emi Weed
}

Prior research on stratification beliefs has investigated individuals' understandings regarding the causes of poverty in America. These past studies have uncovered demographic characteristics associated with individualist and structuralist explanations for poverty. In the current study, we will argue that Americans, like social scientists, envision poverty as a heterogeneous and complex phenomenon. We utilize a cultural cognition theoretical approach to conceptualize these understandings of poverty as schemas. We contend that a schema of poverty contains a set of unique associations regarding both demographic beliefs (who the poor are) and causal attributions (why they are poor). Using original data in a mixed-methods design that incorporates inductive and experimental components, we find that people differentiate between two key types of poverty: intergenerational poverty and downward mobility. People perceive each type of poverty as caused by a different set of factors and as experienced by a different group of people. The type of poverty envisioned is, in most cases, as important as or more important than a respondent's own demographic characteristics in predicting what type of causal attributions he or she makes for poverty. These findings underscore the importance of investigating different schemas of poverty in future stratification beliefs research.

The authors wish to thank Mark Chaves, who supervised this project as part of the Logic of Inquiry course at Duke University. This study would not have been possible without his guidance and generous provision of funding. The authors also wish to thank Lynn Smith-Lovin for her support of this research project. Naomi Quinn and Claudia Strauss also provided eminently helpful feedback on this paper. This research was supported by a grant (T32 AG000139) from the

National Institute on Aging to Patricia Homan. Authors are listed in alphabetical order. All authors contributed equally. Please address correspondence concerning this article to Lauren Valentino, Duke University, Department of Sociology, 276 Sociology/Psychology Building, Box 90088, 417 Chapel Drive, Durham, NC 27708-0088 USA. E-mail: lauren.valentino@duke.edu. 
The United States carries the untoward distinction of being one of the wealthiest countries in the world, yet having one of the highest rates of poverty among Western democracies (Smeeding 2005). Social scientists have long sought to understand this paradox, and have generally attributed it to Americans' political reticence to support anti-poverty policies (Brady 2009; Gans 1995; Gilens 1999). What drives the lack of support for anti-poverty policy in the United States? Some scholars have suggested the American emphasis on rugged individualism and self-reliance (Bellah et al. 1985; Esping-Anderson 1990), while others have suggested out-and-out racism (Clawson 2002; Clawson and Trice 2000; Gilens 1999). A substantial body of research has identified beliefs about the causes of poverty as key predictors of support for welfare and other redistributive policies (Bullock, Williams, and Limbert 2003; Feagin 1975; Kluegel and Smith 1986; Shirazi and Biel 2005). Thus, an understanding of America's persistent anti-poor sentiment and restrictive welfare policy requires a careful examination of public beliefs and perceptions regarding who the poor are and why they are poor.

Indeed, sociologists have investigated Americans' beliefs about poverty and inequality over the past forty years, generating a rich subfield known as stratification beliefs (Kluegel and Smith 1981). ${ }^{1}$ Much of this stratification beliefs research has focused on individuals' explanations for why people are poor, often referred to as causal attributions for poverty (Cozzarelli, Wilkinson, and Tagler

\footnotetext{
${ }^{1}$ For a recent, thorough review of this entire literature, see Hunt and Bullock (2016).
} 
2001). Numerous studies have identified important demographic correlates of causal attributions and have developed sophisticated understandings of individuals' beliefs. Yet this research has primarily studied poverty as a uniform, homogeneous phenomenon, despite recent advances in sociological research that have documented the various and diverse types of poverty in the United States (Cellini, McKernan, and Ratcliffe 2008; Corcoran 1995; Solon 1992; Tickamyer and Duncan 1990). Researchers in this tradition have previously touched on the importance of studying whether different types of poverty elicit different causal attributions (e.g., Robinson 2009; Wilson 1996), but these ideas have generally gone untested.

We address this gap in the literature through a two-stage mixed-methods design. First, we inductively assess people's understandings of poverty using structured interviews. Next, we use these interviews to construct a survey that includes new items of poverty beliefs that reflect both interviewees' understandings of poverty and empirical facts about poverty from the current sociological literature on stratification.

Finally, we utilize the theoretical concept of cultural schemas to identify the constituent parts of beliefs about poverty. To do so, we rely on the connectionist theory of cognition, which implies that individuals have mental models that are composed of associations between concepts (D'Andrade 1995; Strauss and Quinn 1997). Although previous research has employed the notion of schemas to investigate people's understandings about the causes of racial inequality (Edgell 
and Tranby 2007), we are, to our knowledge, the first to operationalize and apply the insights of schema theory to beliefs about poverty. In their foundational work on stratification beliefs, Kluegel and Smith $(1986,16)$ briefly mention schemas and suggest how they may be relevant to beliefs about poverty, but this aspect of their work has remained largely undeveloped. We concretize schemas of poverty as shared mental models of who is poor and why they are poor. We then demonstrate that people's perceptions regarding types of poverty differ in these two key respects, employing a survey-experiment to show that this is the case.

This study provides a much-needed update to the stratification beliefs literature. It demonstrates the utility of coupling inductive approaches (such as interviewing) with survey and experimental approaches. Furthermore, our findings reveal a novel category of attributions for poverty-interactionismindicating that Americans' understandings of the causes of poverty go beyond the individualist and structuralist categories that have characterized the literature for decades. We also show how applying schema theory to stratification beliefs provides a clearer elaboration of how people understand poverty. By prompting people to envision a specific type of poverty, we show that the type of poverty envisioned by the respondent is, in most cases, as important-or even more important-a predictor of causal attributions as the demographic correlates found in previous stratification beliefs research.

\section{Background}

The primary methodology for most studies investigating causal attributions 
of poverty was pioneered by Joe Feagin (1975). Feagin administered a survey that listed several possible reasons for poverty, or causal attributions, and asked respondents to rate the importance of each. He then categorized the list of possible causes into three main types of reasons for poverty, which remain the most commonly used and accepted types today (see, for example, Adeola 2005; Bobo 1991; Bobo and Kluegel 1993; Hunt 1996, 2004; Merolla, Hunt, and Serpe 2011; Robinson 2009). These three types of attributions are individualist, in which people locate the cause of poverty in the personal traits and behaviors of the poor; structuralist, in which people locate the cause outside the individual in the features of society; and fatalist, in which people locate the cause of poverty in non-human factors such as fate, bad luck, or God's will. Fatalist attributions are generally found to be uncommon reasons for poverty in the United States, and as a result are often omitted from analyses (see, for example, Cozzarelli, Wilkinson, and Tagler 2001; Hunt 1996). Although studies have occasionally referenced an additional type of attribution (as discussed below), the majority of published research has focused on individualism and structuralism. Feagin's original survey format was foundational in the study of stratification beliefs and has been subsequently employed primarily to study the causal attributions of poverty and Black-White inequality (Hunt 2007; Kluegel 1990; Kluegel and Bobo 1993), in addition to a wide variety of other beliefs (Adeola 2005; Hunt 1996, 2004; Nilson 1981; Shirazi and Biel 2005; Kluegel and Smith 1986; Smith and Stone 1989).

In this line of research, individualism and structuralism are not 
conceptualized as opposing ends of a single spectrum (Kluegel and Smith 1986; Hunt and Bullock 2016). The consensus of several decades of research is that these are instead two related, but distinct, types of beliefs that people may hold in combination, sometimes called "dual consciousness," "split consciousness," "compromise," or "mixed" explanations (Hunt 1996; Hunt 2004; Kluegel and Smith 1986; Kluegel and Bobo 1993; Kluegel, Mason, and Wegener 1995; Lee, Jones, and Lewis 1990; Merolla, Hunt, and Serpe 2011). ${ }^{2}$ Although seemingly contradictory, this pattern of adherence to both individualism and structuralism is quite common, especially among racial minorities (Hughes and Tuch 1999; Hunt 2004). Thus, high levels of structuralism do not necessarily correspond to low levels of individualism.

Although Feagin's approach has dominated stratification beliefs research in the United States, an important line of research in Europe has employed an alter- native approach (Lepianka, Van Oorschot, and Gelissen 2009). Based on the Eurobarometer survey (Riffault and Rabier 1977), this European strain of poverty beliefs research asks respondents to make a forced choice between four reasons for poverty. Both approaches have strengths and weakness, as noted by Lepianka, Van Oorschot, and Gelissen (2009). However, given the interpretation difficulties in the European research and the incompatibility of the forced-choice format with the dual consciousness patterns commonly observed in the United

\footnotetext{
${ }^{2}$ For detailed theoretical discussions of dual/split consciousness, see Hunt and Bullock (2016) and Kluegel, Mason, and Wegener (1995).
} 
States, we continue our research within the tradition established by Feagin.

Up to now, most stratification beliefs research has focused on two main areas: identifying time trends in causal attributions of poverty, and uncovering the characteristics of respondents that predict the type of attributions they are most likely to make for poverty. Americans are consistently found to be more individualist than structuralist in their attributions for poverty (Adeola 2005; Cozzarelli, Wilkinson, and Tagler 2001; Feagin 1975; Kluegel and Smith 1986; Shirazi and Biel 2005). However, there is some evidence of regional and temporal variation (Hunt and Bullock 2016). For example, Hunt (1996) finds that Californians in the early 1990s score higher in structuralism than individualism, and he suggests that difficult economic or social conditions may foster structuralist ideologies that challenge American's general tendency toward individualism.

Research on the demographic correlates of attributions has shown that women are more structuralist in their attributions than men (Hunt 2004; Kluegel 1987; Merolla, Hunt, and Serpe 2011; Shirazi and Biel 2005) and non-Whites are more structuralist than Whites (Adeola 2005; Cozzarelli, Wilkinson, and Tagler 2001; Feagin 1975; Hunt 1996, 2004; Merolla, Hunt, and Serpe 2011). Several studies have also found that racial minorities score higher than Whites on both individualism and structuralism (Bullock, Williams, and Limbert 2003; Hunt 1996, 2004; Merolla, Hunt, and Serpe 2011); these findings support the concept of "dual consciousness." The literature has been mixed on the relationship between 
education and structuralism, but has generally found a negative relationship between education and individualism (e.g., Feagin 1975; Hunt 1996, 2004; Kluegel and Smith 1986; Nilson 1981). Findings regarding the relationship between income and attributions for poverty have also been quite mixed (Adeola 2005; Feagin 1975; Merolla, Hunt, and Serpe 2011; Nilson 1981). Finally, political conservatives are generally more individualist in their attributions for poverty than liberals, who are more structuralist (Cozzarelli, Wilkinson, and Tagler 2001; Kluegel and Smith 1986; Zucker and Weiner 1993).

Although this body of research has uncovered important patterns in Americans' beliefs, scholars have recently identified some key areas for further research, including two primary gaps that the present study aims to address. First, much of the current literature relies on an undifferentiated conception of poverty, as highlighted by Hunt and Bullock (2016), Lepianka, Van Oorschot, and Gelissen (2009), Strauss (2002), and Wilson (1996). Social scientists who study poverty are well aware that there are many different types of poverty (intergenerational and downward mobility, urban and rural, etc.), but the methodology of extant research in stratification beliefs has not allowed for an examination of whether the public perceives more than one type of poverty. As Wilson notes, "the use of an undifferentiated conception of poverty in prior survey research has precluded the possibility that the public may have different causal beliefs for different types of poverty" $(1996,414) .^{3}$

\footnotetext{
${ }^{3}$ Prior research has also suggested a distinction between the "deserving" and "undeserving" poor (e.g., Gans 1995; Gilens 1999). Future work should explore the relationship between the two
} 
One of the only attempts to remedy this oversight was undertaken by Wilson (1996). He investigated three different types of poverty-welfare dependency, homelessness, and impoverished migrant laborers. He found that individuals hold different causal beliefs for each specific type of poverty and that these beliefs are linked to the perceived race of the poor. Wilson's respondents favored individualist attributions for welfare dependency and saw welfare dependents as consisting of more Blacks. By contrast, respondents favored structuralist attributions for homelessness and believed the homeless to be more White. A mixed or in-between explanation was favored for migrant laborers, who were perceived as mostly Latino. Wilson's findings lead us to ask the following research questions:

$Q_{1}$ : What do people have in mind when thinking about poverty? Without being prompted, do people tend to perceive and distinguish between different types of poverty, rather than holding a single overarching conception of poverty? And if so, what are these types of poverty that readily come to mind?

To better understand how distinctions within the broad concept of poverty may shape causal attributions, we take an inductive approach. Rather than selecting a few of the numerous types of poverty that seem important to researchers, we explore respondents' thought processes through cognitive interviews and allow any distinctions to naturally emerge. In this way, we hope to

schemas of poverty uncovered here, intergenerational poverty and downward mobility, and the degree of "deservingness" attributed to the individual. 
uncover key pat- terns of thinking that will be relevant to stratification beliefs for researchers moving forward.

In addressing this first series of research questions, we conceptualize people's beliefs about poverty as cultural schemas. Schema theory provides a framework for testing the specific contents of beliefs about poverty. Fundamentally, schemas are cognitive networks used to categorize and link concepts (D'Andrade 1995; Strauss and Quinn 1997). Each concept is cognitively linked to others by learning and experience, creating models of what is typical. Cultural schemas are cognitive schemas that are shared across individuals. We assert that different types of poverty correspond with different cultural schemas. For example, Strauss (2000) has shown that Americans have a cultural schema for welfare recipients, which typically calls to mind the image of the welfare queen-a prototypical individual with certain characteristics. Russo, one of Strauss's interviewees, explicates this "welfare queen" association: "some poverty-stricken woman, all she knows how to do is have kids. One after another ... she's never been educated to the fact that she should get off her butt and go to work. So she brings up like five or six kids [with] the same attitude and they do the same thing again" (quoted in Strauss 2000, 84).

Thinking about welfare recipients may also prompt other ideas alongside the demographics and character traits, including environments, such as ghetto, city, or subsidized housing; current events, such as social welfare programs in Chicago or New York; and any other beliefs, ideas, or understandings that a 
person has come to associate with the word "welfare." Importantly, thinking of another type of poverty prompts an entirely different set of associated ideas. This is consistent with Strauss's finding that "most U.S. Americans have multiple, inconsistent schemas for thinking about the causes of poverty" $(2002,58)$. We argue that schemas of poverty contain at least two constituent parts: beliefs about the kind of people who are poor and beliefs about the reasons they are poor. Wilson's research illustrates the importance of identifying these schemas and cataloguing their differences. We therefore ask the following research question:

$Q_{2}$ : Can each type of poverty be conceptualized as a schema that contains unique beliefs about (1) who the poor are, and (2) why they are poor?

If we do observe distinct schemas of poverty, what is their significance? How important are they in the landscape of stratification beliefs? Prior research has identified respondents' gender (Hunt 2004; Kluegel 1987; Merolla, Hunt, and Serpe 2011; Shirazi and Biel 2005), race (Adeola 2005; Cozzarelli, Wilkinson, and Tagler 2001; Feagin 1975; Hunt 1996, 2004; Merolla, Hunt, and Serpe 2011), and political ideology (Cozzarelli, Wilkinson, and Tagler 2001; Kluegel and Smith 1986; Zucker and Weiner 1993) as consistent predictors of their causal attributions for poverty. Other studies have pointed out further differences in attributions in terms of religion (Feagin 1975; Hunt 2002), income (Adeola 2005; Feagin 1975; Merolla, Hunt, and Serpe 2011), education (Kluegel 1987; Merolla, Hunt, and Serpe 2011), and age (Cozzarelli, Wilkinson, and Tagler 2001; Feagin 
1975). We therefore ask:

$Q_{3}:$ Is the type of poverty as important as (or more important than) respondents' own demographic characteristics in predicting what type of causal attribution for poverty they make?

The second gap in the literature we address involves the specific content of the causal attribution items. Feagin's survey instruments, developed in the mid-970s, are still being used in almost the original wording today. As a result, many of the now-traditional causal attribution survey items have not been updated or expanded, despite significant change in the public discourse surrounding poverty over the past forty years (Strauss and Quinn 1997). Although there have been a few studies that have incorporated different survey items (e.g., Cozzarelli, Wilkinson, and Tagler 2001; Hopkins 2009; Smith and Stone 1989), scholars who have comprehensively reviewed this literature make suggestions such as "future work should strive to develop and implement a wider set of survey items in an effort to shed further light on untapped and underexamined dimensions of beliefs" (Hunt and Bullock 2016, p. 108). Thus, in order to incorporate new dis- course and public understandings concerning cultural explanations for poverty that have developed over the past forty years, we begin with Feagin's original survey items and update this list of attributions to include twenty-four additional items, primarily based on Strauss's (2012) analysis of public discourse, Smith and Stone (1989), and Cozzarelli, Wilkinson, and Tagler's (2001) study. (See appendix tables A2-A4 for a list of survey items 
grouped according to factor analysis.)

Given the widespread and continued reliance on Feagin's original survey items, it is not surprising that most research still emphasizes the three types of causal explanations for poverty that Feagin found in his first set of studies: individualist, structuralist, and fatalist. However, a handful of studies that introduced new items have identified a fourth type of explanation (Cozzarelli, Wilkinson, and Tagler 2001; Nilson 1981; Smith and Stone 1989), leading scholars to question the exhaustiveness of Feagin's original three-part typology (Hunt and Bullock 2016; Lepianka, Van Oorschot, and Gelissen 2009). Nilson (1981) identified an "institutional" category of causal attributions that included the education system, corporations, and trade unions; however, subsequent research (e.g., Kluegel and Smith 1986; Cozzarelli, Wilkinson, and Tagler 2001) finds that rather than being distinct, these items align closely with other indicators of structuralism.

Smith and Stone (1989) and Cozzarelli, Wilkinson, and Tagler (2001) identify a fourth category of explanation for poverty that they call "culturalism" and "cultural attributions," respectively. For Smith and Stone, culturalism does not contain a unique set of attribution items; rather, it is measured simply as a combination of adherence to individualism and structuralism (1989, pp. 99-100). Thus, their notion of culturalism is more consistent with a "dual consciousness" pattern of belief than an entirely new type of explanation for poverty. Cozzarelli, Wilkinson, and Tagler's (2001) cultural attribution category includes items 
typically considered individualist ("being born with low IQ") and structuralist ("having to attend bad schools"; "jobs the poor can get are low paying"), in addition to new items reflecting intergenerational processes ("breakdown of the nuclear family"; "being born into poverty"). In furthering this line of inquiry, we include "breakdown of the nuclear family," but we find that being born into poverty is not in itself an explanation for poverty so much as a key schematic distinction people make in the process of attributing causes of poverty.

Despite their inconsistencies, these prior studies point to the presence of a meso-level category of explanation for poverty that is located between individual dispositions and macro-structural circumstances. This category remains underidentified, and its importance in poverty beliefs has not been well documented, in part because of the reliance of Feagin's original survey items. Therefore, our final research question is:

$Q_{4}:$ When we update causal attributions to reflect current public discourse on poverty, do we uncover any novel types or categories of attributions?

\section{Methods}

Interviews: Data Collection

We began to address our first research question by conducting cognitive inter- views using traditional and updated survey items. The survey consisted of the twenty-four newly added attributions alongside Feagin's original twelve, for a total of thirty-six possible attributions. We used purposive sampling from an extended network of personal contacts to recruit a sample that included a wide 
variety of different races, ages, genders, socio-economic statuses, geographic locations, political orientations, and religious beliefs. We employed this selective sampling approach because probability sampling is not an effective strategy for small interview projects, as a relatively large $\mathrm{N}$ is necessary to ensure that the sample accurately represents the makeup of the broader population. Heterogeneous purposive sampling allowed us to select individuals who represent a broad range of demographic groups. Though not strictly representative, purposive sampling is useful for first-stage data collection when inductive conclusions are subjected to further experimental testing to demonstrate the generalizability of observed trends. The final sample was composed of fourteen men and women between ages 18 and 88. One respondent self-identified as Asian, two as Latino/a, two as Native American, one as mixed race, and eight as White. Two respondents had an elementary education, two had high school diplomas, two had associate's degrees, and eight had bachelor's degrees. Interviewees also spanned the United States, with respondents from the Southeast, Southwest, Northeast, Midwest, and Pacific Northwest regions.

We conducted these cognitive interviews as a test of the viability of the revised survey measures. The thirty-six attribution items were divided into three equal groups and distributed as a guided survey to the fourteen interviewees. In keeping with standard cognitive interviewing techniques (Beatty and Willis 2007), interviewees were led through an online or paper version of the survey by one of 
the researchers. For each question, interviewees were asked to think through every detail of the question out loud, first by restating what the question was asking of them in their own words, and then by narrating their thought process in arriving at one of the multiple-choice answers provided in the survey.

Interviews: Analytic Strategy

During our cognitive interviews, respondents reported confusion as to how to answer the survey questions about attributions for poverty. Therefore, we began coding for themes in the issues they raised, and this coding resulted in a prominent theme: interviewees consistently refused to provide their opinions about causal attributions for poverty without first knowing what type of person was being discussed. The most common distinction drawn was between people who were not born poor but became poor over the course of their lives, and those who were born into, or raised in, poverty. As such, the two separate schemas of poverty identified by these interviews-downward mobility and intergenerational poverty-arose inductively.

\section{Survey Experiment: Data Collection}

Following the cognitive interviews, we developed a new survey that would allow us to differentiate between causal beliefs about the downwardly mobile and the intergenerationally poor. To answer questions 2 and 4, the survey employed an experimental design with three conditions: general poverty; those who are born poor and remain poor (intergenerational poverty); and those who are not born poor but become poor during their lifetimes (downward mobility). A total of 
602 respondents were randomly assigned to one of the three conditions. Each of the three conditions consisted of an identical survey except for the wording of the prompting questions. For example, those in the general poverty condition were asked "why people are poor in America" $(\mathrm{N}=202)$, whereas those in the downward mobility condition were asked "why people who are not born poor become poor during their lifetime in America" $(\mathrm{N}=204)$, and the intergenerational condition asked respondents "why people who are born poor remain poor in America" $(\mathrm{N}=196) .{ }^{4}$

To examine people's understandings of causal attributions of poverty for each type, we included the thirty-six survey items that were pretested in the cognitive interview stage. Respondents were asked to rate each item in terms of its role in causing their assigned type of poverty on a four-point scale, ranging from "not at all important" to "very important," with a fifth "don't know or not familiar with this statement" option. The order of the items was randomized for each respondent.

To examine people's understandings of what kind of people make up each type of poverty, the survey asked respondents to describe imagined demographic characteristics of the poor using sliding scales for four demographic factors: race, age, gender, and immigrant status. Respondents were provided sliders for different categories of each factor, and sliders for each factor were aligned so that they always summed to a total of 100 percent. For example, gender

\footnotetext{
${ }^{4}$ Respondents were required to answer all attribution and demographic belief questions. Nonresponses were permitted for respondents' own demographic characteristics, with percentage missing data ranging from 0 to 2.16 percent for the variables used in these analyses.
} 
consisted of two categories: male and female. Respondents indicated what proportion of the poor they were envisioning were male or female. If they slid the female slider to indicate a majority, the male slider would indicate a minority of men, for a constant total. The order of demographic characteristics of the poor was also randomized for each respondent.

Finally, we collected standard demographic information from each respondent, such as gender, race, political orientation (on a seven-point scale), income and employment status, educational attainment, age, state and rurality/urbanicity of residence, and religious affiliation and attendance.

We fielded this survey experiment in March 2014 using Amazon's Mechanical Turk (MTurk), a data pool that has been found to yield samples comparable to random-digit-dialing techniques and population-based Internet surveys (Simons and Chabris 2012; Weinberg, Freese, and McElhattan 2014). ${ }^{5}$ Because we employ an experimental design, a perfectly representative sample of the US population is not necessary. Rather, the validity of our conclusions depends upon the randomization of subjects into control and experimental groups (see Singleton and Straits [2009]; Webster and Sell [2007]; and Zelditch

\footnotetext{
${ }^{5}$ The use of MTurk is becoming increasingly common in social science research. Several recent studies have employed MTurk and have reported high-quality samples that rival or exceed traditional samples in terms of representativeness (see for example Horton, Rand, and Zeckhauser 2011; Hunzaker 2014; Simons and Chabris 2012; Weinberg, Freese, and McElhattan 2014). Respondents who are MTurk "workers" select into the survey, and are solicited based on small reimbursement for their participation (i.e., 35 cents per completed task). We therefore expect that these findings are representative of MTurk workers who selected into this survey. In the case of this survey, we find that the sample is slightly younger, slightly more male, more college educated, having a lower income, slightly less conservative, and much less Protestant than the US population (see table A1). However, as discussed above, this poses little threat to the validity or generalizability of our conclusions.
} 
[1969] for further discussion of generalizability, representativeness, and experimental methods). As table 1 below indicates, survey respondents in each of the three conditions were not significantly different from one another in terms of age, gender, college education, race, income, political orientation, or religion between conditions, demonstrating the successful randomization of respondents across conditions.

Table 1. Sample Characteristics by Condition

\begin{tabular}{llll}
\hline & General poverty & Intergenerational & Downward mobility \\
\hline Age & 36.4 & 34.4 & 34.8 \\
Male & $51.50 \%$ & $59.18 \%$ & $54.41 \%$ \\
College educated & $51.49 \%$ & $44.90 \%$ & $51.47 \%$ \\
White & $76.73 \%$ & $73.98 \%$ & $75.98 \%$ \\
Income & $\$ 47,925.46$ & $\$ 46,781.06$ & $\$ 49,405.09$ \\
Conservatism" & 3.49 & 3.37 & 3.21 \\
Protestant & $23.27 \%$ & $23.98 \%$ & $18.14 \%$ \\
Total participants & 202 & 196 & 204 \\
\hline \multicolumn{5}{r}{ NOTE: No statistically significant differences were observed at the $p<.05$ level. } \\
1Conservatism is measured on a scale of 1 to 7, where 1 is "very liberal" and 7 is \\
\multicolumn{4}{c}{ "very conservative." }
\end{tabular}

However, it is possible that a lack of perfect representativeness could potentially pose a threat to the generalizability of our findings if the criteria for selection into the sample were to interact with the experimental treatment. Compared with the US population (table A1), our sample is somewhat more educated, more liberal, and less religious. Therefore, as an additional precaution, we interacted political ideology, education, and religion with the experimental condition to see if the perceptions associated with each schema vary according to these characteristics. If the effects did vary according to these characteristics, 
this would provide evidence that our results may not be generalizable to the US population. However, neither respondent's political ideology nor education level nor religious affiliation yielded a significant interaction for any outcome. Moreover, no model fit was improved by AIC or BIC standards when a politicalideology-specific, education-specific, or religion-specific effect was introduced into the model; and this held for all of the outcomes. (These results are available from authors upon request.) This gives us confidence that our main results do not vary by political ideology, education, or religion, and that our findings are therefore not likely to be biased by the slight underinclusion of Protestants, conservatives, and less educated respondents in our sample. ${ }^{6}$

\section{Survey Experiment: Analytic Strategy}

To answer the second research question regarding the contents of poverty schemas and how they differ, we use two approaches. For part 1, in which we assess beliefs about who the poor are, we use two-sample equality of proportion tests to determine whether the percentage of the poor perceived to be in each demo- graphic group varies across conditions. For part 2, in which we identify the types of attributions respondents make, we employ factor analysis. We then use ANOVA to test whether the differences in the mean factor scores vary across conditions. To answer the third research question regarding the relative

\footnotetext{
${ }^{6}$ Although we have shown that the sample composition does not impact our between-condition comparisons (our main finding), within the conditions we might expect our sample to place slightly less importance on individualism than the US population. Prior research in stratification beliefs has tended to find that conservatives rate individualist attributions as more important reasons for poverty compared to liberals (Cozzarelli, Wilkinson, and Tagler 2001; Kluegel and Smith 1986; Zucker and Weiner 1993).
} 
importance of the schemas compared to demographic traits of respondents, we estimate a series of regression models. To answer the fourth research question, in which we pinpoint how many different types of attributions respondents make, we utilize both exploratory and confirmatory factor analysis techniques.

\section{Findings}

\section{Multiple Types of Poverty}

The cognitive interviews revealed that individuals perceive multiple types of poverty. We found that interviewees had different ideas of poverty which, in turn, entailed different beliefs about who the poor are and why they are poor. When interviewees were asked to reflect on their beliefs about poverty in the United States, we found that most made a strong distinction between those who are born poor and those who become poor during their lifetimes. This distinction was so central to interviewees' thought processes that many felt they could not make causal attributions or describe who they envision as poor without first anchoring their response in an understanding of the poverty as either intergenerational or downward mobility. This suggested to us that rather than a single generic concept of poverty, there are at least two distinct schemas of poverty: one regarding intergenerational poverty, and one regarding downward mobility.

Below is an example from an interview with Bob, ${ }^{7}$ which illustrates the existence of these two distinct schemas and how they relate to different beliefs. When asked to what extent he felt the poor were personally to blame for their

\footnotetext{
${ }^{7}$ All names are pseudonyms.
} 
economic condition, Bob noted:

Well, if they're born into poverty they are not to blame... Lots of people can't work their way out no matter how much effort they put in... But if they become poor they are somewhat to blame. ${ }^{8}$

Further, this distinction has important implications for who is envisioned as poor and why they are poor. Tim demonstrates that in addition to there being two very distinct types of poverty that immediately come to mind, different types of poverty are associated with different types of people. When asked to rate the importance of "lack of opportunity" as a cause of poverty, Tim said:

Well, like those Black folks in Oakland. They get shot at every day, they can't go to work without gettin' shot, they can't do nothin'. But I guess there's other [White] folks that just spend all their money and buy the big house they can't afford, ain't got no damn sense. So that's not opportunity. They're just stupid. But most White folks do okay, I guess, them Blacks have the biggest problem, so I guess l'd say [opportunity] is some- what important. 'Cause they're just mindin' their business and some- body shot 'em.

Tim went on to further discuss the racial differences between Blacks and Whites in attitudes toward spending, saving, and retirement that contribute to poverty. Tim weighed the two types of poverty by deciding which is more common, before assessing lack of opportunity as a reason for poverty. While he believes lack of opportunity is an important reason for why Black people find

\footnotetext{
${ }^{8}$ These quotes are representative of the tone of the cognitive interviews more generally. Twelve of the fourteen interviewees differentiated between different types of poverty without prompting, and ten made the distinction between being born into and falling into poverty.
} 
themselves in intergenerational poverty, he sees this as much less important for White people, who, in his understanding, generally suffer downward mobility as a result of their own poor choices. Since the survey question inquired generically about poverty, in the end he settled on the middle-ground response of "somewhat important."

Another interviewee, Will, noted that he was splitting the difference between intergenerational poverty and downward mobility when responding aloud to standard survey questions about poverty. Though particular to some attributes (e.g., "lack of effort" and "failure of society to provide schools"), Will felt that the importance of reasons for poverty depended on whether the poor individual was intergenerationally impoverished or downwardly mobile. As he quipped, “it's harder to lose what you've got than get what you don't have." Sam echoed Will's point, saying, "It matters where you start," and then further elaborating: "A person's starting point has a big effect."”

These interviews reveal the extent to which people differentiate between the intergenerationally poor and the downwardly mobile in terms of their understandings of the population of the poor and their reasons for being impoverished. Strikingly, this distinction emerged inductively through cognitive pretesting of the survey instrument, suggesting that people indeed conceptualize different types of poverty, rather than holding one undifferentiated schema of poverty. Our survey results provide further evidence of the importance of this

\footnotetext{
${ }^{9}$ Quotes were selected for clarity. Although male interviewees are primarily quoted here, their statements are representative of the sample at large.
} 
distinction.

Differences in Beliefs about Who the Poor Are

Survey respondents in the two experimental conditions, intergenerational poverty and downward mobility into poverty, were asked to describe the poor in terms of race, age, gender, and immigrant status. We used two-sample equality of proportion tests to examine whether respondents estimated different proportions of these groups across experimental conditions. The results are shown in figure 1. Of the four demographic characteristics, only gender had no statistically significant difference between the intergenerational poverty and downward mobility conditions.

Figure 1. Percentage of the Envisioned Poor Within Demographic Categories

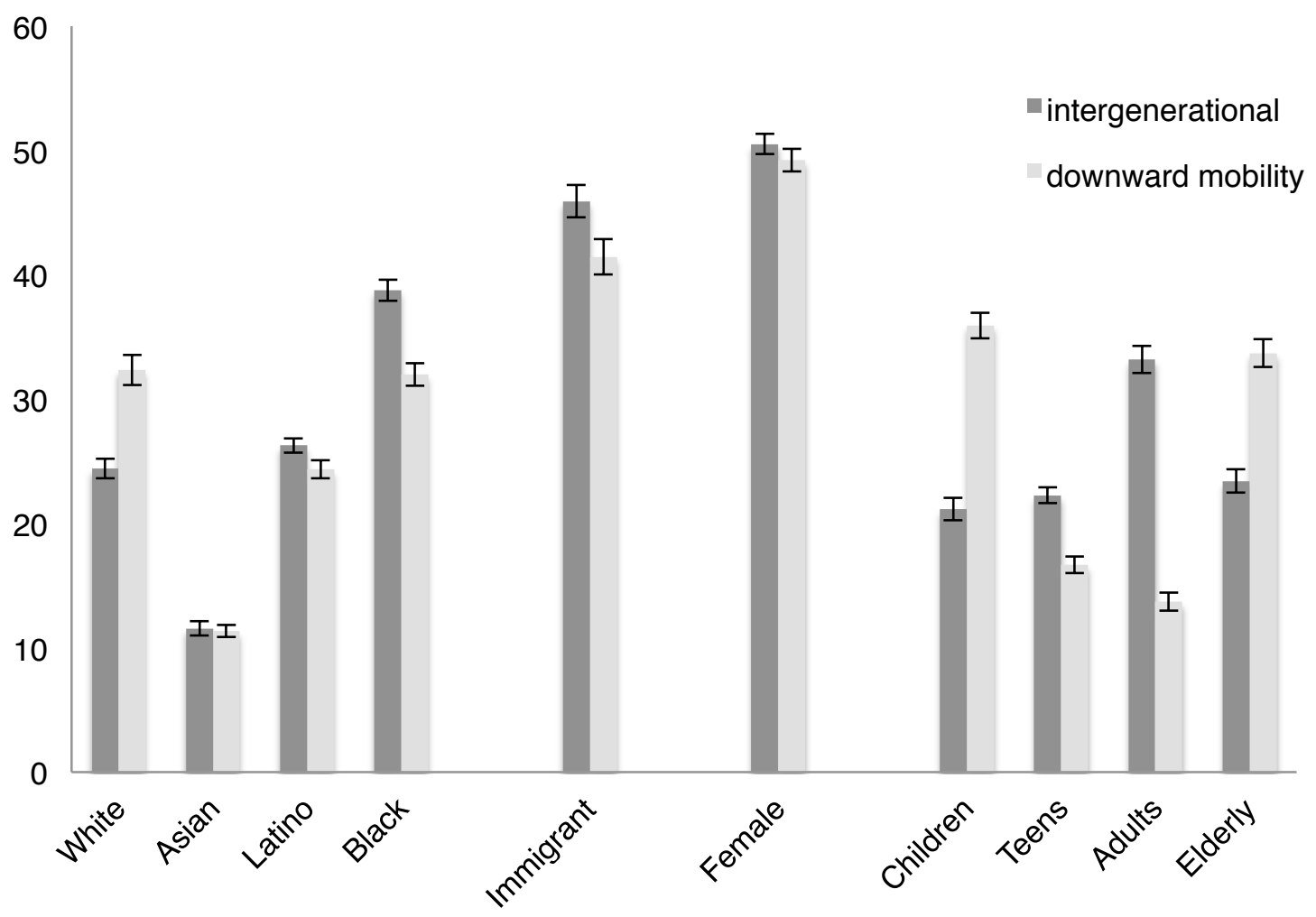


Race

On average, respondents in the downwardly mobile condition estimated that those who are not born poor but become poor made up 32.3 percent Whites and 32.0 percent Blacks. By contrast, respondents in the intergenerationally poor condition envisioned those who are born poor to be only 21.4 percent White but 38.8 percent Black. In total, when asked to estimate the percentage of poor people for each race, people in the downward mobility condition envisioned the downwardly mobile as more White, compared to those in the inter- generational condition, who thought of the intergenerationally poor as more Latino and more Black. There were no significant differences between the ways people primed to think of downward mobility or intergenerational poverty estimated the proportion of Asians. ${ }^{10}$

Immigrant Status

Immigrants were envisioned to constitute a slightly higher percentage of the poor among respondents in the intergenerational condition. Respondents estimated that 45.9 percent of individuals born into poverty are immigrants, compared to 41.4 percent of the downwardly mobile.

Age

Respondents were given four age categories: children, teenagers, adults,

\footnotetext{
${ }^{10}$ These race-based differences in perceptions of who the poor are undoubtedly reflect not only schemas of poverty, but schemas related to race and racism in the United States as well. For instance, some research has argued that Whites oppose welfare because they perceive welfare recipients as more likely to be Black (Gilens 1996). We might therefore expect that if respondents link welfare receipt to intergenerational poverty, race-based perceptions of the intergenerationally poor help explain this opposition to welfare.
} 
and the elderly. When asked to estimate the percent of poor people by age group, respondents primed to consider the downwardly mobile thought of the poor as 35.9 percent children, compared with respondents asked to consider those in intergenerational poverty, who estimated a lower proportion of children at 21.1 percent. ${ }^{11}$ By contrast, respondents estimated that adults make up 13.7 percent of the downwardly mobile poor, compared to 33.1 percent of the intergeneration- ally poor. People in the downward mobility condition generally envisioned the downwardly mobile as consisting of more children and more elderly, compared to those in the intergenerational condition, who envisioned the intergenerationally poor as composed of more teenagers and more adults.

Differences in Beliefs about Why the Poor Are Poor

In keeping with prior causal attributions research methodology, we began by conducting an exploratory factor analysis using principal components analysis with a varimax rotation to group the thirty-six attribution measures into categories representing the types of attributions people make when explaining the causes of poverty (Cozzarrelli, Wilkinson, and Tagler 2001; Hunt 1996). The results of the exploratory factor analysis produce attributions that are consistent with prior research: the expected individualist and structuralist factors emerged with all the traditional items aligning with those from prior studies. For example, the individualist factor includes personal irresponsibility, lack of effort, and lack of thrift. The structuralist factor includes prejudice and discrimination, low wages,

\footnotetext{
${ }^{11}$ This finding that children are thought of as more downwardly mobile is an interesting, and in many ways counterintuitive, one that highlights the need for further research into the details of these two schemas of poverty.
} 
and failure of society to provide good schools. ${ }^{12}$ IIIness and disability were seen as a unique reason for poverty and did not align with any other attribution items in the factor analysis. This highlights an area of opportunity for future research.

In addition to the two primary factors from prior research, individualism and structuralism, the exploratory factor analysis revealed a third factor that we term interactionist. This factor represents the type of meso-level attribution that prior research has attempted to identify-it occupies the space between the individual level and societal level. Interactionism captures the interpersonal, interactive, and contextual features of poverty. It includes family, peers, role models, gangs, and children. This type of attribution may have entered public conscious- ness after the highly publicized "culture of poverty" debates in the 1960s and 1970s (see for example Lewis 1959, 1961; Valentine 1968). We avoid the term "cultural" for our new category of attributions, in part because "culture of poverty" type explanations can include both individualist and interactionist items. Furthermore, while interactionist items are relational, they are not necessarily explicitly cultural in nature.

In order to conduct a more rigorous test of whether interactionism is truly a distinct category of causal attribution, we employ confirmatory factor analysis on the entire dataset. We use structural equation modeling in Mplus to confirm that individualism, structuralism, and interactionism are indeed unique factors.

\footnotetext{
${ }^{12}$ Three items that are traditionally considered indicators of fatalism (fate, bad luck, and God's will) were included in the survey experiment and exploratory factor analyses, but as was the case in previous studies, very few participants rated these causes as important. We thus do not show results for fatalism here, but these results are available upon request.
} 
Specifically, we test four different models-one model with the three unique factors, and three models with interactionist items subsumed under individualism and/or structuralism-and examined these models' goodness-of-fit using four measures of model fit (AIC, BIC, RMSEA, and CFI). Table 2 below indicates that all measures of model fit are significantly worsened when interactionism is not considered a unique factor: $\mathrm{AIC}, \mathrm{BIC}$, and RMSEA are larger in all of the twofactor models, and CFI is smaller in the two-factor models. That the three- factor model-the one including individualism, structuralism, and interactionism-is the best fitting supports our assertion that interactionism is indeed a unique and previously unidentified type of attribution.

Table 2. Attribution Measurement Model Fit Statistics

\begin{tabular}{|c|c|c|c|c|c|}
\hline Model & Description & AIC & $\mathrm{BIC}$ & RMSEA & CFI \\
\hline $\begin{array}{c}\text { Three-factor } \\
\text { model }\end{array}$ & $\begin{array}{l}\text { Includes individualism, } \\
\text { structuralism, and } \\
\text { interactionism as unique } \\
\text { factors }\end{array}$ & 39525 & 39956 & .055 & .908 \\
\hline $\begin{array}{c}\text { Two-factor } \\
\text { model }\end{array}$ & $\begin{array}{l}\text { Subsumes all } \\
\text { interactionist items } \\
\text { under individualism }\end{array}$ & 39791 & 40214 & .064 & .873 \\
\hline $\begin{array}{c}\text { Two-factor } \\
\text { model }\end{array}$ & $\begin{array}{l}\text { Subsumes all } \\
\text { interactionist items } \\
\text { under structuralism }\end{array}$ & 40198 & 40620 & .076 & .820 \\
\hline $\begin{array}{c}\text { Two-factor } \\
\text { model }\end{array}$ & $\begin{array}{l}\text { Subsumes interactionist } \\
\text { items under } \\
\text { individualism and } \\
\text { structuralism }\end{array}$ & 40032 & 40454 & .071 & .842 \\
\hline
\end{tabular}

NOTE: Smaller values of AIC, BIC, and RMSEA are preferred, while larger values of CFI are preferred.

Based on the confirmatory factor analysis, we construct factor scores for 
individualism, structuralism, and interactionalism for each respondent based on the importance ratings they assign to each item in the factor. These factor scores represent the degree to which a respondent makes each type of attribution for poverty. These types of attributions are not on a single spectrum and thus are not mutually exclusive. It is therefore possible for respondents to score high (or low) on all types of attributions. The correlations among the factors suggest that they capture distinct understandings of the causes of poverty: consistent with prior research, individualism and structuralism share a modest negative correlation ( $R$ $=-.407, \mathrm{p}<.001$ ), while individualism and interactionism share a strong positive correlation $(\mathrm{R}=.724, \mathrm{p}<.001)$, though there is no significant correlation between interactionism and structuralism $(R=.032, p>.05)$. These correlations highlight the uniqueness of interactionism as an attribution: although it seems related to individualism, interactionism is orthogonal to structuralism.

Figure 2 displays the mean differences in attributions by condition. Looking at these means, we can see that respondents believe that the intergenerational poor and the downwardly mobile are poor for different reasons, an affirmative answer to our second research question. Respondents in the intergenerational condition make more structuralist and more interactionist attributions than those in the downward mobility condition, who make more individualist attributions. 
Figure 2. Mean Differences in Attribution by Condition

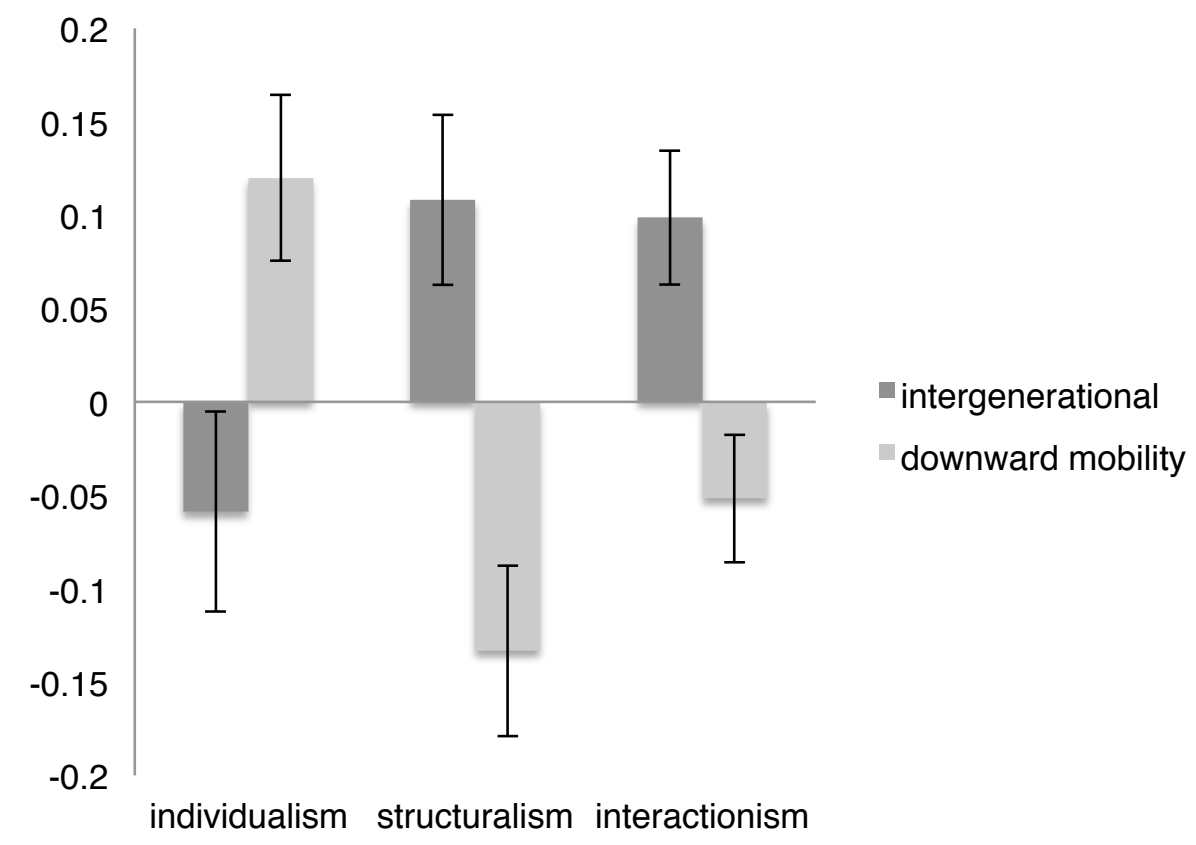

If we consider each specific item (potential cause of poverty), five out of twelve individualist items are significantly more likely to be ranked as "very important" causes of downward mobility into poverty. These items include alcoholism and drug abuse, making bad choices, choosing to engage in criminal activity, personal irresponsibility, and lack of thrift. No individualist cause of poverty was ranked as more important for intergenerational poverty than downward mobility, further reinforcing the notion that overall, individualism is more closely associated with downward mobility than intergenerational poverty (see table A2 in the appendix for differences between condition for each individualist item).

Looking at the specific items (potential causes of poverty) that we categorize as "structuralist," eight out of twelve were ranked as significantly more 
important causes of poverty for intergenerational poverty than for downward mobility: failure of society to provide good schools, lack of opportunity, not having the right contacts, lack of public services, prejudice/discrimination in policing, prejudice/discrimination in promotions and wages, prejudice/discrimination in hiring, and being taken advantage of by the rich. One item was ranked as a significantly more important cause of poverty for downward mobility, failure of business to provide enough jobs. All in all, the individual item results for structuralist causes of poverty support the conclusion that structuralism is more associated with the intergenerational schema of poverty (see table $A 3$ in the appendix for differences between condition for each structuralist item).

Turning to interactionist attributions, three out of the six items are significantly more important for intergenerational poverty than downward mobility. These include negative role models, influence of peers, and presence of gangs. These differences among individual items bolster the idea that interactionism is associated with the intergenerational schema of poverty (see table A4 in the appendix for differences between conditions for each interactionist item).

\section{The Role of Type of Poverty in Causal Attribution}

Previous research on causal attributions of poverty has focused on the demographic characteristics of respondents that lead them to make more structuralist, individualist, or fatalist attributions. Yet we suggest that the type of poverty envisioned may be as or more important in terms of predicting the type of causal attribution a respondent makes. We assess the relative importance of the 
type of poverty (research question 3) by regressing respondents' structuralist, individualist, and interactionist attribution scores on respondents' demographic characteristics as well as the type of poverty about which they were questioned. The dependent variables are latent constructs resulting from the factor analyses that combine multiple indicators of each attribution and are z-standardized. Therefore, we employ linear regression to model the effect of demographic characteristics and type of poverty on structuralism, individualism, and interactionism.

As table 3 reveals, the type of poverty that a respondent has in mind is an important predictor of whether she will make individualist, structuralist, and/or interactionist attributions for that poverty. We find, once again, that thinking of downward mobility causes the respondent to make more individualist attributions than those who consider intergenerational poverty or poverty in general; it also causes the respondent to make less structuralist attributions than those who consider intergenerational poverty or poverty in general; and it causes the respondent to make less interactionist attributions for poverty compared to those who consider intergenerational poverty. Looking at the other demographic characteristics in table 3, we see that the respondent's gender does not predict individualism, or interactionism, although women are more likely than men to be structuralist. A one-standard-deviation increase in conservatism leads to a significant increase in individualism, a significant decrease in structuralism, and a significant increase in interactionism. Non-Whites are more likely to score higher 
than Whites on all attributions, supporting the idea that the split consciousness described by Hunt and Bullock (2016) and Kluegel, Mason, and Wegener (1995) applies not just to individualism and structuralism, but to interactionism as well.

Table 3. Predictors of Attribution

\begin{tabular}{|c|c|c|c|}
\hline & Individualism & Structuralism & Interactionism \\
\hline Female & $-.041(.052)$ & $.159^{\star *}(.048)$ & $.046(.042)$ \\
\hline Conservatism ${ }^{1}$ & $.244^{\star \star \star}(.028)$ & $-.298^{\star \star \star}(.026)$ & $.083^{\star \star \star}(.023)$ \\
\hline Non-white $^{2}$ & $.172^{\star \star}(.061)$ & $.122^{*}(.056)$ & $.147^{\star \star}(.050)$ \\
\hline Age & $.001(.002)$ & $-.000(.002)$ & $.003(.002)$ \\
\hline College degree ${ }^{3}$ & $-.029(.052)$ & $-.127^{\star \star}(.048)$ & $.008(.042)$ \\
\hline Income ${ }^{4}$ & $-.012(.017)$ & $-.027(.015)$ & $-.022(.014)$ \\
\hline \multicolumn{4}{|l|}{ Religion $^{5}$} \\
\hline Non-Christian & .152 (.088) & $-.035(.081)$ & $.106(.071)$ \\
\hline None & $.048(.085)$ & $-.010(.078)$ & $-.013(.068)$ \\
\hline \multicolumn{4}{|l|}{ Condition ${ }^{6}$} \\
\hline $\begin{array}{l}\text { General poverty } \\
\text { Intergenerational }\end{array}$ & $-.220^{* \star}(.063)$ & $.236^{\star \star}(.058)$ & $-.011(.051)$ \\
\hline poverty & $-.202^{* *}(.063)$ & $.279^{\star * \star}(.058)$ & $.153^{* *}(.051)$ \\
\hline \multicolumn{4}{|l|}{ Constant } \\
\hline \multicolumn{4}{|c|}{$\begin{array}{l}{ }^{1} \text { Conservatism was measured on a scale of } 1 \text { to } 7 \text {, where } 1 \text { is "very liberal" and } 7 \text { is "very } \\
\text { conservative." Here, we standardize it such that the coefficients represent a one-standard } \\
\text { deviation change in political conservatism. } \\
{ }^{2} \text { Nonwhite includes Black/African American; Hispanic/Latino; Asian or Pacific Islander; } \\
\text { American Indian, Eskimo or Alaska Native; multi-racial; and other } \\
{ }^{3} \text { Reference category is less than college degree. } \\
{ }^{4} \text { Income represents logged annual household earnings. } \\
{ }^{5} \text { Reference category is Christian (includes Protestants, Catholics, Mormon, non- } \\
\text { denominational Christian, Quaker, and Evangelical), whereas non-Christian includes Jewish, } \\
\text { Muslim, Buddhist, as well as other (agnostic, Pagan, Shintoist, spiritual, Wiccan). } \\
{ }^{6} \text { Reference category is downward mobility. }\end{array}$} \\
\hline
\end{tabular}

Age is not significantly related to type of attribution (nor did supplemental analyses - not shown here-find a nonlinear effect of age). We find that having a college degree is related to being less structuralist (compared to those who do 
not have at least a college degree), although it is unrelated to individualism and interactionism. Neither income nor religion appear to be associated with any attribution. Finally, the type of poverty a respondent had in mind is a significant predictor of causal attribution for individualism, structuralism, and interactionism, with the single exception of general poverty being indistinguishable from downward mobility for interactionism.

In fact, when we compare effect sizes among predictors of attribution, we see that the type of poverty is generally a more important predictor of causal attribution than gender, race, age, education, income, and religion for all three types of attributions. ${ }^{13}$ Political views are the only factor that appears to be more important than type of poverty in predicting attribution. Table 3 shows that a onestandard-deviation increase on the conservatism scale (which represents a dramatic shift in political orientation, such as going from slightly liberal to slightly conservative) leads to a .244 increase in the latent variable individualism. This same increase in conservatism leads to a .298 decrease in structuralism, and a .083 increase in interactionism. Thus, although political views remain arguably the most important predictor of causal attributions of poverty, type of poverty envisioned is very important, and, in fact, more important than a respondent's race, gender, age, education level, income, and religion.

\footnotetext{
${ }^{13}$ While comparing effect sizes among variables of different measurement scales is a rough approximation of their relative effects, we use two metrics to do so: first, we note that gender, race, education, and religion are all dummy variables, and their comparison to type of poverty (also a dummy variable) is therefore straightforward. Second, of the three continuous variables (age, income, and conservatism), only conservatism is a significant predictor of attribution. We compare the standardized effect of conservatism to the type of condition, while acknowledging that this comparison is rough at best.
} 


\section{Discussion and Conclusion}

This study provides empirical and theoretical advancements for the field of stratification beliefs. Using a novel mixed-methods design, we investigate people's beliefs about poverty and employ the framework of cultural schemas in order to systematically understand these beliefs. First, we inductively uncovered multiple types of poverty that people have in mind when they think about the poor. Our cognitive interviews revealed that people tended to draw a clear distinction between those who are born poor (the intergenerationally poor) and those who become poor during their lifetime (the downwardly mobile).

Next, we operationalized schemas of poverty, arguing that these cultural schemas can be thought of as composed of who people envision as poor and why those people are poor. We employed a survey-experiment design to systematically investigate whether intergenerational poverty and downward mobility into poverty are fundamentally different in these two respects. We find that they are.

Compared to the downwardly mobile poor, people envision the intergenerationally poor as more Black, more Latino, more immigrants, and more teens and adults. They envision the downwardly mobile as being composed of more Whites, fewer immigrants, and more children and elderly compared to the intergenerationally poor. People are more likely to attribute the intergenerationally poor's socioeconomic status to structuralist causes (such as lack of good schools and prejudice and discrimination) and to interactionist causes (such as role 
models, peers, and gangs), whereas they are more likely to attribute the downwardly mobile's poverty to individualist causes (such as lack of thrift and drug or alcohol use).

This distinction in the type of poverty matters because the type of poverty considered by respondents is generally as important as standard respondent demographic characteristics in predicting the type of attribution a respondent makes. This last point indicates that research in the stratification beliefs tradition has not differentiated type of poverty despite the fact that type of poverty matters greatly in terms of the causes attributed to it. Future research should examine the distribution of schemas of poverty within the population. For example, if most people believe that poverty is primarily composed of the intergenerationally poor, then we can expect these people to have more structuralist understandings of that poverty's causes. In fact, when looking at the control condition of our surveyexperiment (i.e., the unprimed respondents who were asked to consider "the poor in America"), we find that people estimated that 67 percent of the poor were born into that poverty. Future studies employing nationally representative data can pinpoint Americans' beliefs about schemas of poverty-specifically whether they think most of the poor were born into that poverty or transitioned into it via downward mobility.

Finally, we reaffirm the importance of updating research design in the study of stratification beliefs. The clear emergence of a third factor, which we here term "interactionist," confirms what prior research (e.g., Lepianka, Van 
Oorschot, and Gelissen 2009) has begun to suggest: the standard individualist and structuralist types of attributions are not sufficient for explaining how people perceive and explain poverty. Social scientists have long recognized interactionist factors-peers and role models, family formation, gangs-as playing important roles in the lives of the poor. Using information from prior research on discourse analysis and the content of our cognitive interviews, we show that the American public shares this recognition. Unfortunately, because prior research neither asked about many interactionist causes nor distinguished between types of poverty for which these causes are considered more or less important, it is unclear how long these interactionist factors have been an important component of Americans' cultural schemas regarding poverty. On the one hand, it is possible that the shifting discourse about the poor has changed popular understandings of poverty over time. On the other hand, ours is one of the few studies to take an inductive approach to assessing beliefs about poverty, and so perhaps these schemas are relatively stable over time but had never been comprehensively captured by researchers. The inductive emergence of two types of poverty suggests that future research could greatly benefit from employing such grounded techniques in order to better capture people's beliefs about poverty. The mixed-methods approach allows us to triangulate the findings, thereby permitting a richer and more accurate inquiry into the causes of social inequality (Stewart and Sewell 2011). 


\section{Appendix}

\section{Table A1. Comparison of Study Sample to U.S. Population}

\begin{tabular}{|c|c|c|}
\hline & Study sample & U.S. population \\
\hline Age & 35.2 & 37.7 \\
\hline Male & $55.0 \%$ & $49.2 \%$ \\
\hline College educated & $49.3 \%$ & $30.1 \%$ \\
\hline White & $75.7 \%$ & $73.8 \%$ \\
\hline Black & $9.2 \%$ & $12.6 \%$ \\
\hline Asian & $6.2 \%$ & $5.0 \%$ \\
\hline Other $^{1}$ & $8.9 \%$ & $8.6 \%$ \\
\hline Income ${ }^{2}$ & $\$ 40,000$ & $\$ 53,657$ \\
\hline Conservatism & 3.35 & 4.09 \\
\hline Protestant & $21.7 \%$ & $44.6 \%$ \\
\hline
\end{tabular}

NOTE: US population statistics are drawn from the 2014 American Community Survey; political views and religious affiliation are drawn from the 2014 General Social Survey.

${ }^{1}$ In the study sample, "other" includes Native American, multiracial, Hispanic/Latino, and all others. The ACS asks individuals whether they identify their ethnicity as Hispanic or Latino, separate from the race question. Therefore, Hispanic individuals in the ACS could be included in any of the racial categories listed.

${ }^{2}$ Figures represent median household income. 
Table A2. Differences in Individualist Attributions by Condition

$\%$

$\%$ Very Important Cause of Difference Factor

Attribution Item

Poverty

(I-D) Loading

Failure to value education

Intergenerational Downward

Alcoholism/drug abuse

41.8

40.4

1.4

.592

Making bad choices

41.0

61.3

$-20.3^{\star \star \star}$

.548

Choosing to engage in criminal activity

40.3

61.1

$-20.8^{\star \star *} \quad .750$

Lack of effort

40.0

51.0

$-11.0^{\star}$

.732

Failure to set goals

33.2

36.0

$-2.8$

.944

Personal irresponsibility

32.8

30.4

2.4

.837

32.1

48.0

$-15.9^{\star \star \star}$

.967

Lack of ambition

31.8

39.4

$-7.6$

.960

Lack of thrift

27.7

44.8

$-17.1^{\star * *}$

.661

Preference for taking handouts

25.5

30.1

$-4.4$

21.9

21.1

0.8

-

Lack of ability, talent or intelligence

9.7

15.7

$-6.0 \quad .736$

NOTE: A series of z-tests was used to determine if differences in proportions between the experimental conditions were statistically significant. Factor loadings are scaled by the item that contributes most variance to the latent factor (preference for taking handouts).

${ }^{* \star *} p<.001,{ }^{* \star} p<.01,{ }^{*} p<.05$ (two-tailed tests) 
Table A3. Differences in Structuralist Attributions by Condition

\begin{tabular}{|c|c|c|c|c|}
\hline \multirow[b]{2}{*}{ Attribution Item } & \multicolumn{2}{|c|}{$\begin{array}{c}\text { \%Very Important Cause of } \\
\text { Poverty }\end{array}$} & \multirow{2}{*}{$\begin{array}{c}\% \\
\text { Difference } \\
(\mathrm{I}-\mathrm{D})\end{array}$} & \multirow{2}{*}{$\begin{array}{l}\text { Factor } \\
\text { Loading }\end{array}$} \\
\hline & Intergenerational & Downward & & \\
\hline $\begin{array}{l}\text { Low wages in some businesses and } \\
\text { industries }\end{array}$ & 51.1 & 45.1 & 6.4 & .604 \\
\hline Lack of opportunity & 44.9 & 27.6 & $17.3^{\star \star \star}$ & .765 \\
\hline $\begin{array}{l}\text { Failure of society to provide good } \\
\text { schools }\end{array}$ & 43.1 & 20.1 & $23.0^{* * *}$ & .749 \\
\hline Big corporations exploit their workers & 38.3 & 36.6 & 1.7 & .922 \\
\hline Not having the right contacts & 34.2 & 18.6 & $15.4^{* \star *}$ & 618 \\
\hline Prejudice/discrimination in hiring & 33.7 & 22.7 & $11.0^{*}$ & .932 \\
\hline $\begin{array}{l}\text { Failure of business to provide } \\
\text { enough jobs }\end{array}$ & 32.8 & 43.6 & $-10.8^{\star}$ & .509 \\
\hline Prejudice/discrimination in policing & 31.1 & 19.7 & $11.4^{\star *}$ & - \\
\hline $\begin{array}{l}\text { Prejudice/discrimination in } \\
\text { promotions and wages }\end{array}$ & 30.8 & 19.6 & $11.2^{\star \star}$ & .894 \\
\hline Being taken advantage of by the rich & 29.2 & 20.6 & $8.6^{\star}$ & .930 \\
\hline Lack of public services & 27.3 & 15.2 & $12.1^{* *}$ & .841 \\
\hline An unfair tax system & 20.9 & 19.1 & 1.8 & .874 \\
\hline
\end{tabular}

NOTE: Factor loadings are scaled by the item that contributes most variance to the latent factor (prejudice/discrimination in policing).

${ }^{\star \star *} \mathrm{p}<.001,{ }^{* \star} \mathrm{p}<.01,{ }^{*} \mathrm{p}<.05$ (two-tailed tests) 
Table A4. Differences in Interactionist Attributions by Condition

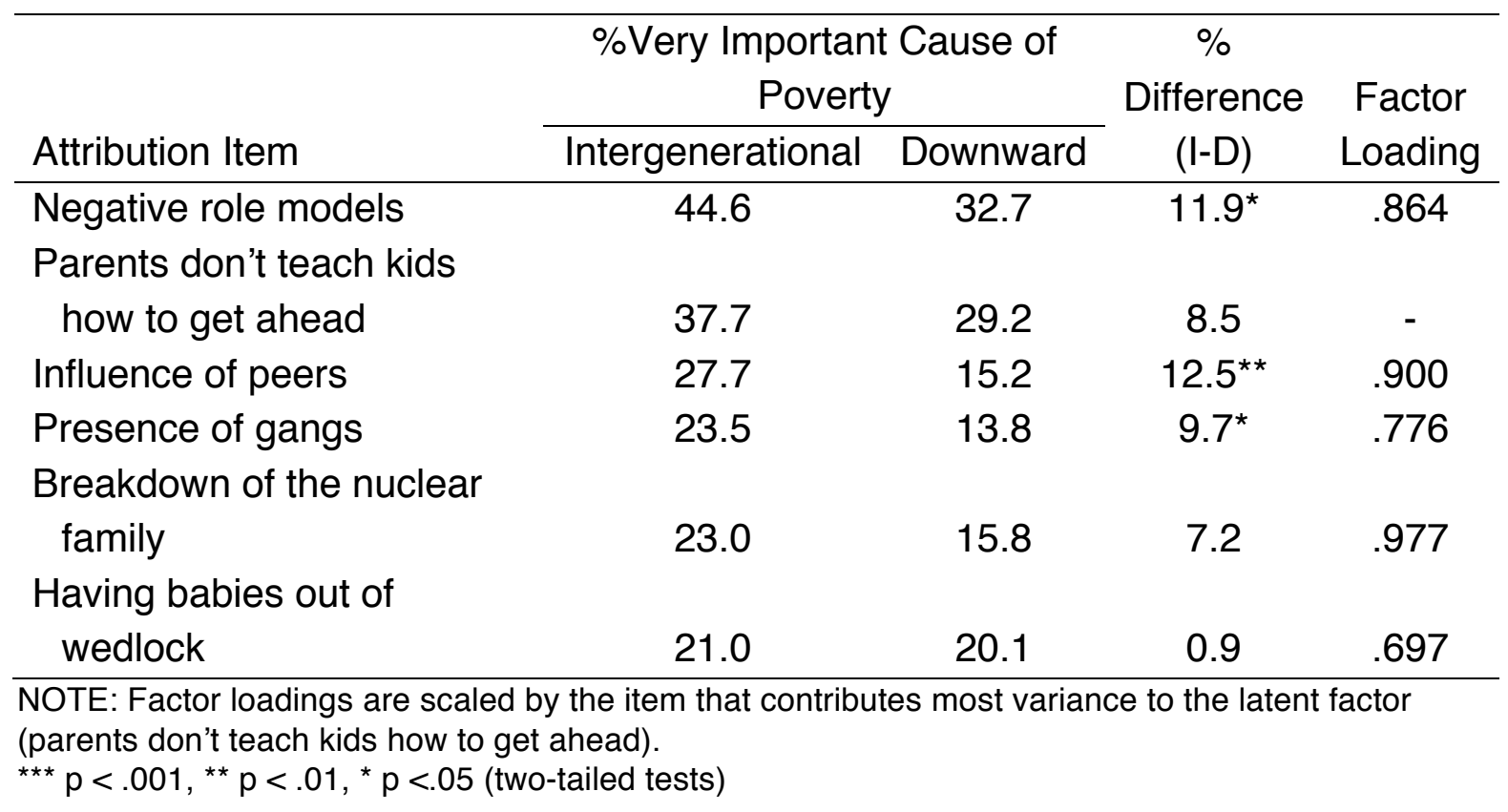




\section{About the Authors}

Patricia Homan is a doctoral candidate in sociology at Duke University, and a pre-doctoral trainee in the NIA-Funded T32 Training Program on the Demography of Aging at the Duke University Population Research Institute (DUPRI). Her areas of interest include health, demography, gender, stratification/inequality, and social psychology. Her current research explores how gender and socioeconomic inequalities shape the health of populations and individuals over the life course.

Lauren Valentino is a doctoral candidate in sociology at Duke University. Her areas of interest include culture and cognition, and stratification and inequality. Her current research examines the social patterns in cultural perceptions of the education system, labor market, and social movements. Her previous work has appeared in Social Problems, Social Currents, and Economics of Education Review, among other outlets.

Emi Weed is a doctoral candidate in sociology at Duke University. Her areas of interest include health and wellness, family formation, emotion and bonding, qualitative methods, and social psychology. Her current research is centered around the emotional transitions of new parents as they journey through pregnancy, labor, and delivery, with particular focus on the role of antenatal healthcare providers. 


\section{References}

Adeola, Francis O. 2005. "Racial and Class Divergence in Public Attitudes and Perceptions About Poverty in USA: An Empirical Study." Race, Gender \& Class 12(2):53-80.

Beatty, Paul C., and Gordon B. Willis. 2007. "Research Synthesis: The Practice of Cognitive Interviewing." Public Opinion Quarterly 71(2):287-311. doi:10.1093/poq/nfm006.

Bellah, Robert N., Richard Madsen, William M. Sullivan, Ann Swidler, and Steven M. Tipton. 1985. Habits of the Heart: Individualism and Commitment in American Life. 1st Calif. pbk. ed. Berkeley: University of California Press.

Bobo, Lawrence. 1991. "Social Responsibility, Individualism, and Redistributive Policies." Sociological Forum 6(1):71-92.

Bobo, Lawrence, and James R. Kluegel. 1993. "Opposition to Race-Targeting: Self-Interest, Stratification Ideology, or Racial Attitudes?" American Sociological Review 58(4):443-64. doi:10.2307/2096070.

Brady, David. 2009. Rich Democracies, Poor People: How Politics Explain Poverty. Oxford: Oxford University Press.

Bullock, Heather E., Wendy R. Williams, and Wendy M. Limbert. 2003. "Predicting Support for Welfare Policies: The Impact of Attributions and Beliefs About Inequality." Journal of Poverty 7(3):35.

Cellini, Stephanie R., Signe-Mary McKernan, and Caroline Ratcliffe. 2008. "The Dynamics of Poverty in the United States: A Review of Data Methods, and Findings." Social Problems 27(3):577-605.

Clawson, Rosalee A. 2002. "Poor People, Black Faces: The Portrayal of Poverty in Economics Textbooks." Journal of Black Studies 32(3):352-61.

Clawson, Rosalee A., and Rakuya Trice. 2000. "Poverty as We Know It: Media Portrayals of the Poor." Public Opinion Quarterly 64(1):53-64.

Corcoran, M. 1995. "Rags to Rags: Poverty and Mobility in the United States." Annual Review of Sociology 21:237-67.

Cozzarelli, Catherine, Anna V. Wilkinson, and Michael J. Tagler. 2001. "Attitudes Toward the Poor and Attributions for Poverty." Journal of Social Issues 57(2):207-27. doi:10.1111/0022-4537.00209.

D'Andrade, Roy G. 1995. The Development of Cognitive Anthropology. 
Cambridge: Cambridge University Press.

Edgell, Penny, and Eric Tranby. 2007. "Religious Influences on Understandings of Racial Inequality in the United States." Social Problems 54(2):263-88.

Esping-Anderson, Gosta. 1990. The Three Worlds of Welfare Capitalism. Cambridge: John Wiley \& Sons.

Feagin, Joe R. 1975. Subordinating the Poor: Welfare and American Beliefs. Englewood Cliffs, NJ: Prentice-Hall.

Gans, Herbert J. 1995. The War Against the Poor: The Underclass and Antipoverty Policy. New York: Basic Books.

Gilens, Martin. 1999. Why Americans Hate Welfare: Race, Media, and the Politics of Antipoverty Policy. Chicago: University of Chicago Press.

Hopkins, Daniel J. 2009. "Partisan Reinforcement and the Poor: The Impact of Context on Explanations for Poverty." Social Science Quarterly 90(3):744-64. doi:10.1111/j.1540-6237.2009.00641.x.

Horton, John J., David G. Rand, and Richard J. Zeckhauser. 2011. "The Online Laboratory: Conducting Experiments in a Real Labor Market." Experimental Economics 14:399-425.

Hughes, Michael, and Steven A. Tuch. 1999. "How Beliefs About Poverty Influence Racial Policy Attitudes: A Study of Whites, African Americans, Hispanics, and Asians in the United States." In Racialized Politics: The Debate About Racism in America, edited by D. O. Sears, J. Sidanius, and L. Bobo, 16590. University of Chicago Press.

Hunt, Matthew O. 1996. "The Individual, Society, or Both? A Comparison of Black, Latino, and White Beliefs about the Causes of Poverty." Social Forces 75(1):293-322. doi:10.2307/2580766.

- - . 2002. "Religion, Race/Ethnicity, and Beliefs about Poverty." Social Science Quarterly 83(3): 810-31. doi:10.1111/1540-6237.00116.

- - . 2004. "Race/Ethnicity and Beliefs about Wealth and Poverty." Social Science Quarterly 85(3): 827-53. doi:10.1111/j.0038-4941.2004.00247.x.

- - . 2007. "African American, Hispanic, and White Beliefs about Black/White Inequality, 1977- 2004." American Sociological Review 72(3):390-415. doi:10.2307/25472469.

Hunt, Matthew O., and Heather E. Bullock. 2016. "Ideologies and Beliefs about 
Poverty." In The Oxford Handbook of the Social Science of Poverty, edited by David Brady and Linda Burton, 93-116. Oxford: Oxford University Press.

Hunzaker, M. B. Fallin. 2014. "Making Sense of Misfortune: Cultural Schemas, Victim Redefinition, and the Perpetuation of Stereotypes." Social Psychology Quarterly 77(2):166-84.

Kluegel, James R. 1987. "Macro-Economic Problems, Beliefs about the Poor and Attitudes toward Welfare Spending." Social Problems 34(1):82-99. doi:10.2307/800731.

- - - 1990. "Trends in Whites' Explanations of the Black-White Gap in Socioeconomic Status, 1977- 1989." American Sociological Review 55(4):51225. doi:10.2307/2095804.

Kluegel, James R., and Lawrence Bobo. 1993. "Dimensions of Whites' Beliefs about the Black-White Socioeconomic Gap." In Prejudice, Politics and the American Dilemma, edited by Sniderman, Tetlock, and Carmines, 127-47. Stanford: Stanford University.

Kluegel, James R., David Mason, and Bernd Wegener, eds. 1995. Social Justice and Political Change: Public Opinion in Capitalist and Post-Communist States, vol. 3. New York: De Gruyter.

Kluegel, James R., and Eliot R. Smith. 1981. "Beliefs About Stratification." Annual Review of Sociology 7 (January):29-56.

- - - 1986. Beliefs About Inequality: Americans' Views of What Is and What Ought to Be. New York: Aldine Transaction.

Lee, Barrett A., Sue Hinze Jones, and David W. Lewis. 1990. "Public Beliefs about the Causes of Homelessness." Social Forces 69(1):253-65. doi:10.2307/2579617.

Lepianka, Dorota, Wim Van Oorschot, and John Gelissen. 2009. "Popular Explanations of Poverty: A Critical Discussion of Empirical Research." Journal of Social Policy 38(3):421-38. doi:10.1017/ S0047279409003092.

Lewis, Oscar. 1959. Five Families: Mexican Case Studies in the Culture of Poverty. New York: Basic Books.

- - - 1961. The Children of Sanchez: Autobiography of a Mexican Family. New York: Random House.

Merolla, David M., Matthew O. Hunt, and Richard T. Serpe. 2011. "Concentrated Disadvantage and Beliefs about the Causes of Poverty: A Multi-Level Analysis." 
Sociological Perspectives 54(2):205-28.

doi:10.1525/sop.2011.54.2.205.Nilson, Linda Burzotta. 1981. "Reconsidering Ideological Lines: Beliefs about Poverty in America." Sociological Quarterly 22(4):531-48.

Riffault, Helene, and Jaques Rene Rabier. 1977. The Perception of Poverty in Europe. Commission of the European Communities.

Robinson, James W. 2009. "American Poverty Cause Beliefs and Structured Inequality Legitimation." Sociological Spectrum 29(4):489-518. doi:10.1080/02732170902904681.

Shirazi, Rez, and Anders Biel. 2005. "Internal-External Causal Attributions and Perceived Government Responsibility for Need Provision: A 14-Culture Study." Journal of Cross-Cultural Psychology 36(1): 96-116. doi:10.1177/0022022104271428.

Simons, Daniel J., and Christopher F. Chabris. 2012. "Common (Mis)Beliefs about Memory: A Replication and Comparison of Telephone and Mechanical Turk Survey Methods." PLOS ONE 7(12):e51876. doi:10. 1371/journal.pone.0051876.

Singleton, Royce A., and Bruce C. Straits. 2009. Approaches to Social Research, 5th ed. Oxford: Oxford University Press.

Smeeding, Timothy M. 2005. "Public Policy, Economic Inequality, and Poverty: The United States in Comparative Perspective." Social Science Quarterly 86(December):955-83. doi:10.1111/j.0038-4941. 2005.00331.x.

Smith, Kevin B., and Lorene H. Stone. 1989. "Rags, Riches, and Bootstraps: Beliefs about the Causes of Wealth and Poverty." Sociological Quarterly 30(1):93-107.

Solon, Gary. 1992. "Intergenerational Income Mobility in the United States." American Economic Review 82(3):393-408.

Stewart, Quincy Thomas, and Abigail A. Sewell. 2011. "Quantifying Race: On Methods for Analyzing Social Inequality." In Rethinking Race and Ethnicity in Research Methods, edited by John H. Stanfield II, 209-34. New York: Routledge.

Strauss, Claudia. 2000. "The Culture Concept and the Individualism-Collectivism Debate: Dominant and Alternative Attributions for Class in the United States." In Culture, Thought, and Development, edited by Larry Nucci, Geoffrey B. Saxe, Elliot Turiel, 71-99. Hove, U.K.: Psychology Press. 
- - . 2002. "Not-So-Rugged Individualists: U.S. Americans' Conflicting Ideas About Poverty." In Work, Welfare and Politics: Confronting Poverty in the Wake of Welfare Reform, edited by Frances Fox Piven, Joan Acker, Margaret Hallock, and Sandra Morgen, 55-72. Eugene: University of Oregon Press.

- - . 2012. Making Sense of Public Opinion: American Discourses About Immigration and Social Programs. Cambridge: Cambridge University Press.

Strauss, Claudia, and Naomi Quinn. 1997. A Cognitive Theory of Cultural Meaning. Cambridge: Cambridge University Press.

Tickamyer, Ann R., and Cynthia M. Duncan. 1990. "Poverty and Opportunity Structure in Rural America." Annual Review of Sociology 16:67-86.

Valentine, Charles A. 1968. Culture and Poverty: Critique and CounterProposals. Chicago: University of Chicago Press.

Webster, Murray Jr., and Jane Sell, eds. 2007. Laboratory Experiments in the Social Sciences. Burlington, MA: Elsevier.

Weinberg, Jill D., Jeremy Freese, and David McElhattan. 2014. "Comparing Data Characteristics and Results of an Online Factorial Survey between a PopulationBased and a Crowdsource-Recruited Sample." Sociological Science 1:292-310.

Wilson, George. 1996. "Toward a Revised Framework for Examining Beliefs about the Causes of Poverty." Sociological Quarterly 37(3):413-28.

Zelditch, Morris. 1969. "Can You Really Study an Army in the Laboratory?" In $A$ Sociological Reader on Complex Organizations, edited by A. Etzioni, 531-39. New York: Holt, Rinehart and Winston.

Zucker, Gail Sahar, and Bernard Weiner. 1993. "Conservatism and Perceptions of Poverty: An Attributional Analysis." Journal of Applied Social Psychology 23(12):925-43. doi:10.1111/j.1559-1816.1993.tb01014.x. 